\title{
Patrones temporales de recuento de células somáticas, grasa, proteína y nitrógeno ureico en leche de estanque y su asociación con fertilidad en ganado lechero en la zona centro-sur de Chile
}

\author{
Temporal patterns of bulk tank somatic cell count, fat, protein, and urea nitrogen and \\ their association with fertility in Central-Southern Chilean dairy cattle \\ PJ Pinedo ${ }^{\mathrm{a}, \mathrm{b}^{*}}$, P Meléndez ${ }^{\mathrm{a}, \mathrm{c}}$ \\ ${ }^{a}$ College of Veterinary Medicine, University of Florida, Gainesville, USA. \\ 'Insecabio Ltda., Los Angeles, Chile. \\ ${ }^{c}$ Escuela de Medicina Veterinaria, Universidad Santo Tomás, Viña del Mar, Chile.
}

\begin{abstract}
SUMMARY
The objective of this study was to describe and evaluate the dynamics of bulk tank (LE) somatic cell counts (RCS), milk urea nitrogen (NUL), fat $(\%)$ and protein $(\%)$ and to analyze their association with reproductive indexes, considering monthly LE samples from 187 farms $(\sim 12,000$ dairy cows at any time) in Central-Southern Chilean dairy cattle from 1997 to 2007. Reproductive indexes included in the study were calving to first service interval (IPPS, d), calving to conception interval (IPP, d) and services per conception (SC). Bulk tank LNRCS was positively associated with herd size, milk yield (305 mature equivalent), milk solids and NUL. Bulk tank NUL was positively associated with milk yield and LE RCS. Average calving to first service interval was $92.5 \mathrm{~d}$ and showed a positive association with LE protein percentage and NUL. Average calving to conception interval was $138.9 \mathrm{~d}$ and was positively associated with LE NUL. It is concluded that the most significant changes in LE components during the last 10 years, in Central-Southern Chilean Holstein cattle, corresponded to a decrease in RCS and an increase in NUL. Changes in RCS reflect an improvement in mammary health, milk quality and milk yield. Bulk tank NUL concentrations were high during the last 5 years in study and depended on factors such as milk production, protein percentage, month and year. Bulk tank NUL was the milk component with the most notorious association with reproductive parameters. More data about protein nutrition should be evaluated in this Chilean cattle population.
\end{abstract}

Palabras clave: bovinos, leche, recuento células somáticas, nitrógeno ureico, fertilidad.

Key words: cattle, milk, somatic cell counts, urea nitrogen, fertility.

\section{INTRODUCCIÓN}

Durante las últimas décadas la industria lechera ha utilizado el análisis de leche de estanque (LE) para monitorear la calidad de la leche, estimar los niveles de mastitis subclínica en los rebaños y detectar la presencia de patógenos causantes de mastitis. De este modo, los productores lecheros han incluido este análisis como una importante herramienta en el control de la sanidad y calidad de su producto (Emanuelson y Funke 1991, Jayarao y col 2004).

El recuento de células somáticas (RCS) de la leche de estanque ha sido usado extensivamente como un indicador de la salud mamaria en rebaños lecheros (Schukken y col 1990). Los valores de LE RCS son una función de la prevalencia de las infecciones intramamarias dentro del rebaño y constituyen un indicador clave de la calidad de la leche (Wenz y col 2007). Losinger (2005) estimó que la reducción en producción de leche asociada con el incremento en LE RCS registrado en planteles lecheros durante el año

Aceptado: 08.07.2009.

* pinedop@ vetmed.ufl.edu
1996 causó una pérdida de 810 millones de dólares a la economía de los Estados Unidos. Consecuentemente, en varios países, incluyendo Chile, las plantas procesadoras de leche han implementado pautas de pago con valores diferenciados de acuerdo a los LE RCS de cada rebaño (Emanuelson y Funke 1991, Tadich y col 2003).

Desde mediados de los 70, los productores lecheros chilenos en la región centro-sur han importado genética Holstein desde Estados Unidos y Canadá con el propósito de mejorar la composición y los niveles de producción de leche (Elzo y col 2004). Los valores genéticos para producción de grasa y proteína han sido considerados como criterios en la selección de toros, en parte debido a que en Chile durante años se ha aplicado un sistema de pago que incluye grasa, proteína y LE RCS.

Otros componentes del análisis de leche de estanque, tales como nitrógeno ureico (NUL), pueden ser usados como una herramienta de manejo en el monitoreo del estatus nutricional de las vacas lecheras. Este es un método rápido y no invasivo que permite estimar la excreción de nitrógeno (Jonker y col 1999) y es considerado como una alternativa para inferir las concentraciones de NUL a nivel individual en el rebaño (Arunvipas y col 2004). 
El área centro-sur reúne aproximadamente el $25 \%$ del total de la población ganadera del país. En esta región geográfica una empresa dedicada al control lechero y servicios agropecuarios (INSECABIO Ltda.) ha monitoreado durante los últimos 20 años una población estable de aproximadamente 12.000 vacas lecheras (predominantemente Holstein), distribuidas en 187 rebaños. Debido a la aplicación de sistemas de mejoramiento genético, avances en prácticas de manejo y cambios en el mercado, esta población ha incrementado sus niveles de producción de leche en el tiempo (Meléndez y Pinedo 2007) y este cambio se ha acompañado por variaciones en la calidad y composición de la leche y la fertilidad de los rebaños.

La asociación entre los componentes de la leche y fertilidad ha sido reportada con anterioridad (Buckley y col 2003, Patton y col 2007), con una asociación negativa entre niveles de NUL y fertilidad constantemente descrita (Godden y col 2001, Hojman y col 2004). Sin embargo, la dinámica de las variaciones en estos componentes y su relación con el rendimiento reproductivo no ha sido descrita en los sistemas lecheros de esta región en particular.

Nuestra hipótesis fue que la composición de la leche de estanque, incluyendo RCS y NUL, ha cambiado en el tiempo y que los niveles de sus componentes están asociados con variaciones en los parámetros reproductivos del ganado lechero de la zona centro-sur de Chile. Los objetivos de este estudio fueron describir y evaluar la dinámica de RCS, NUL, porcentaje de grasa y proteína y analizar su asociación con índices reproductivos, considerando muestras mensuales de leche de estanque de 187 rebaños lecheros ( 12.000 vacas lecheras) en la zona centro-sur de Chile entre los años 1997 y 2007.

\section{MATERIAL Y MÉTODOS}

\section{REBAÑOS LECHEROS Y MANEJO}

El estudio consideró registros de 187 rebaños lecheros en la zona centro-sur de Chile (latitud $36^{\circ} 00^{\prime}$ a $38^{\circ} 30^{\prime}$ sur y longitud $71^{\circ} 00^{\prime}$ oeste hasta el Océano Pacífico). Esta área presenta un clima templado con pluviometría concentrada en el invierno (1.380 mm/año) y temperaturas que van desde $0{ }^{\circ} \mathrm{C}$ en invierno hasta una máxima de $34^{\circ} \mathrm{C}$ en verano ${ }^{1}$.

Los planteles lecheros incluidos en este estudio consistieron en ganado Holstein $(\sim 90 \%)$ y cruzas entre Frisón Europeo $\times$ Holstein $(\sim 10 \%)$. Los animales eran mantenidos en patios de sacrificio (dry lot) $(\sim 40 \%)$, patios techados (free-stalls) $(\sim 40 \%)$, pastoreo $(\sim 10 \%)$ y sistemas mixtos $(\sim 10 \%)$. La alimentación se basaba en a) raciones totalmente mezcladas (TMR) consistentes en silo de maíz, heno de alfalfa y concentrado (50\%); b) concentrado agregado sobre la ración base, silo de maíz y alfalfa cortada y presentada en verde $(\sim 30 \%)$; c) pastoreo $(\sim 10 \%)$; y

Instituto Geográfico Militar. Mapas de Chile. Disponible en http://www.igm.cl (Agosto 05, 2007). d) sistemas mixtos $(\sim 10 \%)$. El manejo reproductivo consistía de inseminación artificial $(\sim 80 \%)$, servicio natural $(\sim 10 \%)$ y la combinación de ambos sistemas $(\sim 10 \%)$. La frecuencia de ordeño era $3 \times(35 \%)$ o $2 \times$ por día $(65 \%)$ usando equipos de ordeña comerciales.

DISEÑO

El estudio consistió en el análisis de datos históricos generados por una organización certificada de control lechero oficial (INSECABIO LTDA., Los Ángeles, Chile). Se analizó información proveniente de 11.790 muestras de leche de estanque colectadas mensualmente en una población 12.000 vacas lecheras, distribuidas en aproximadamente 95 rebaños controlados mensualmente entre enero de 1997 y julio de 2007. Producto de la salida y el ingreso de rebaños al sistema de control lechero durante este periodo, el análisis incluyó un total de 187 rebaños. Las muestras fueron obtenidas por técnicos certificados durante visitas mensuales a los planteles y fueron preservadas por medio de la adición de dicromato potásico. La leche fue analizada en un equipo Combifoss ${ }^{\mathrm{TM}} 5000$ (FOSS, Dinamarca) compuesto de un contador de células somáticas Fossomatic ${ }^{\mathrm{TM}} 5000$ (principio de citometría de flujo) y un componente MilkoScan ${ }^{\mathrm{TM}} 4000$ para el análisis de NUL, grasa y proteína.

La información disponible consistió en un código único de identificación predial e individual, fecha del día de control, número de vacas en ordeña y su distribución por número de lactancia, producción de leche promedio del rebaño el día del muestreo, RCS (células/ml), NUL $(\mathrm{mmol} / \mathrm{L})$, grasa $(\%)$ y proteína $(\%)$ de la muestra de estanque. Para el análisis, los RCS fueron transformados a un puntaje logarítmico lineal (LNRCS), aplicando la fórmula [[Ln (RCS/100.000)]/0,693147] + 3] (Ali y Shook 1980). Los parámetros reproductivos en análisis consistieron en índices promedio por rebaño, en base a la información registrada durante visitas mensuales de los técnicos controladores (i.e., fecha real de parto, fecha real de servicio, días en leche). Los valores descriptivos para la población en estudio durante el período 1997 a 2007 se presentan en el cuadro 1 .

\section{ANÁLISIS ESTADÍSTICO}

Las variables de interés consistieron en el logaritmo del recuento de células somáticas de estanque (LNRCS), NUL (mmol/L) y porcentaje de grasa y proteína láctea del estanque. Las variables reproductivas en consideración fueron: (i) intervalo parto primer servicio del rebaño (IPPS, d), definido como el promedio del número de días transcurridos entre el parto y el subsecuente primer servicio (monta natural o inseminación artificial), incluyendo todas las vacas con al menos un servicio al momento del muestreo; (ii) intervalo parto preñez (concepción) del rebaño (IPP, d), definido como el promedio de días entre el parto y el 
Cuadro 1. Descripción de la población en estudio durante el período 1997-2007. period 1997-2007.

Descriptive statistics for the study population during the

\begin{tabular}{lccccc}
\hline Variable $^{1}$ & Media & $\mathrm{DE}^{2}$ & Mediana & Mín & Máx \\
\hline Tamaño de rebaño & 137 & 106,4 & 112 & 20 & 657 \\
\# de vacas en ordeña & 111 & 86,8 & 88 & 20 & 562 \\
\# de vacas primíparas & 37 & 32,5 & 28 & 5 & 236 \\
ME 305d MY & 7.408 & 17,0 & 7.211 & 2.883 & 14.427 \\
IPPS & 92,5 & 21,1 & 88 & 43 & 290 \\
IPP & 138,9 & 33,8 & 135 & 52 & 463 \\
SC & 1,82 & 0,37 & 1,8 & 1,2 & 5,0 \\
\hline 1 & ME 305d MY = Producción de leche estandarizada a 305 días; IPPS \\
= intervalo parto primer servicio (días); IPP =intervalo parto preñez \\
(días); SC = servicios por concepción. \\
DE = Desviación estándar.
\end{tabular}

servicio (monta natural o inseminación artificial) resultante en una preñez, incluyendo todas las vacas diagnosticadas como preñadas al momento del muestreo; (iii) servicios por concepción del rebaño (SC, unidades), definido como el promedio del número de servicios requerido por las vacas diagnosticadas como preñadas al momento del control durante la lactancia en curso.

Fueron desarrollados modelos lineales generales (GLM) para cada una de las variables de interés para la muestra de estanque (LNRCS, NUL, \% grasa y \% proteína) y para el análisis de los índices reproductivos. Las variables independientes consideradas fueron: número de vacas en ordeña, producción de leche promedio del rebaño el día del muestreo, número de vacas primíparas, promedio de producción de leche estandarizada a 305 días madurez equivalente (ME 305d), rebaño, estación y año de muestreo y rebaño. La definición de las estaciones fue la siguiente; verano $=$ diciembre 1 a febrero 28 ; otoño $=$ marzo 1 a mayo 31 ; invierno = junio 1 a agosto 31 ; y primavera $=$ septiembre 1 a noviembre 30 . Las interacciones biológicamente relevantes se incluyeron en los modelos preliminares, pero fueron removidas cuando resultaron no significativas. De igual manera, las variables independientes cuyos efectos no fueron significativos se removieron en orden descendente de los modelos finales. Las variables de interés fueron, a su vez, incluidas como variables independientes cuando otras variables estaban bajo análisis. Se utilizó el procedimiento GLM de SAS (SAS 9.01, Inst. Inc., Cary, NC) y el efecto de las variables fue considerado significativo cuando $\mathrm{P} \leq 0,05$.

\section{RESULTADOS}

Las medias de los mínimos cuadrados (LSM) para la producción de leche estandarizada (ME 305d), LE LNRCS, LE NUL, LE grasa (\%), LE proteína (\%), IPPS, IPP y SC son presentadas en el cuadro 2 . El cuadro 3 provee las medias de los mínimos cuadrados para las mismas variables, separadas por estación. La dinámica de LNRCS, \% de proteína y $\%$ de grasa de las muestras de estanque a través de los años es presentada en la figura 1.

\section{LNRCS DE ESTANQUE}

El modelo final para LE LNRCS fue altamente significativo $(\mathrm{P} \leq 0,0001)$ y explicó $52,8 \%$ de la variación. Este modelo incluyó como variables independientes: número de vacas en ordeña, número de vacas primíparas, promedio de producción de leche del rebaño durante el día del muestreo, promedio estandarizado de producción de leche (ME 305d), \% de grasa, \% de proteína y NUL de la muestra de estanque, rebaño, estación y año de muestreo y su interacción (cuadro 4). La media para LE LNRCS \pm EE del período completo fue 4,77 $\pm 0,53$. Los

Cuadro 2. Medias de los mínimos cuadrados de las variables en análisis para el ganado lechero de la zona centro-sur de Chile desde 1997 a 2007.

Least squares means of the variables under analysis in central-southern Holstein Chilean cattle from 1997 to 2007.

\begin{tabular}{|c|c|c|c|c|c|c|c|c|c|c|c|}
\hline Item $^{1}$ & 1997 & 1998 & 1999 & 2000 & 2001 & 2002 & 2003 & 2004 & 2005 & 2006 & 2007 \\
\hline ME 305MY & $6.884^{\mathrm{a}}$ & $6.913^{\mathrm{a}}$ & $7.031^{\mathrm{c}}$ & $7.096^{\mathrm{d}}$ & $7.129 \mathrm{de}$ & $7.198^{f}$ & $6.973^{b}$ & $7.135^{\mathrm{de}}$ & $7.157^{\text {ef }}$ & $7.338^{g}$ & $7.439^{h}$ \\
\hline LNRCS & $5,29^{\mathrm{a}}$ & $5,1^{b}$ & $4,87^{\mathrm{c}}$ & $4,87^{\mathrm{c}}$ & $4,84^{\mathrm{c}}$ & $4,86^{\mathrm{c}}$ & $4,75^{\mathrm{d}}$ & $4,68^{\mathrm{e}}$ & 4,66 ef & $4,62^{\mathrm{f}}$ & $4,62^{\mathrm{f}}$ \\
\hline Grasa (\%) & $3,59^{\mathrm{a}}$ & $3,5^{\mathrm{c}}$ & $3,61^{\mathrm{a}}$ & $3,61^{\mathrm{a}}$ & $3,57^{\mathrm{a}}$ & $3,6^{\mathrm{a}}$ & $3,58^{\mathrm{a}}$ & $3,53^{\mathrm{b}}$ & $3,53^{b}$ & $3,58^{\mathrm{a}}$ & $3,58^{\mathrm{a}}$ \\
\hline Proteína (\%) & $3,21^{\mathrm{a}}$ & $3,21^{\mathrm{a}}$ & $3,14^{\mathrm{d}}$ & $3,16^{\mathrm{c}}$ & $3,18^{b}$ & $3,07^{\mathrm{e}}$ & $3,13^{\mathrm{d}}$ & $3,17^{b}$ & $3,18^{b}$ & $3,18^{b}$ & $3,17^{b}$ \\
\hline $\begin{array}{l}\text { NUL } \\
(\mathrm{mmol} / \mathrm{L})\end{array}$ & $4,53^{\mathrm{a}}$ & $5,17^{\mathrm{c}}$ & $5,31^{\mathrm{c}}$ & $5,36^{c}$ & $4,66^{\mathrm{a}}$ & $4,79^{\mathrm{b}}$ & $6,37^{\mathrm{d}}$ & $6,63^{e}$ & $6,32^{d}$ & $6,51^{\mathrm{de}}$ & $7,83^{\mathrm{f}}$ \\
\hline IPPS (días) & $85,0^{\mathrm{a}}$ & $86,3^{\mathrm{b}}$ & $87,4^{\mathrm{c}}$ & $89,7^{\mathrm{d}}$ & $90,9^{\mathrm{e}}$ & $93,9 \mathrm{~g}$ & $91,5^{\mathrm{e}}$ & $95,8^{\mathrm{hi}}$ & $95,3^{\mathrm{h}}$ & $96,7^{\mathrm{i}}$ & $92,5^{\text {ef }}$ \\
\hline IPP (días) & $130,8^{a b}$ & $135,1^{\mathrm{c}}$ & $131,9^{a b}$ & $129,2^{\mathrm{a}}$ & $133,2^{a b c}$ & $137,5^{\mathrm{d}}$ & $133,5^{b c}$ & $142,6^{\mathrm{e}}$ & $145,6^{f}$ & $147,8^{\mathrm{g}}$ & $145,9^{\mathrm{fg}}$ \\
\hline $\begin{array}{l}\mathrm{SC} \\
\text { (unidades) }\end{array}$ & $1,81^{a b}$ & $1,89^{\mathrm{b}}$ & $1,82^{a b}$ & $1,74^{\mathrm{cd}}$ & $1,76^{\mathrm{c}}$ & $1,76^{\mathrm{c}}$ & $1,73^{\mathrm{d}}$ & $1,76^{\mathrm{c}}$ & $1,80^{b}$ & $1,84^{\mathrm{a}}$ & $1,92^{\mathrm{b}}$ \\
\hline
\end{tabular}

a-f Referencias con letras diferentes dentro de las filas indican diferencias estadísticamente significativas $(P \leq 0,05) .{ }^{1} \mathrm{ME} 305 \mathrm{MY}=$ Producción de leche estandarizada a 305 días; LNRCS = logaritmo natural del recuento de células somáticas; $\mathrm{NUL}=$ Nitrógeno ureico en leche; IPPS = intervalo parto primer servicio (días); IPP = intervalo parto preñez (días); $\mathrm{SC}=$ servicios por concepción. 
Cuadro 3. Medias de los mínimos cuadrados de los componentes de la leche de estanque e índices reproductivos en ganado lechero de la zona centro-sur de Chile, presentado por estación, entre los años 1997 y 2007.

Least squares means of LE variables and reproductive indexes in central-southern Holstein Chilean cattle by season between 1997 and 2007

\begin{tabular}{lcccc}
\hline Variable $^{1}$ & Verano & Otoño & Invierno & Primavera \\
\hline ME 305MY & $7.148^{\mathrm{a}}$ & $7.167^{\mathrm{a}}$ & $7.090^{\mathrm{a}}$ & $7.065^{\mathrm{b}}$ \\
LNRCS & $4,81^{\mathrm{a}}$ & $4,79^{\mathrm{a}}$ & $4,86^{\mathrm{a}}$ & $4,86^{\mathrm{a}}$ \\
Grasa (\%) & $3,59^{\mathrm{a}}$ & $3,60^{\mathrm{a}}$ & $3,57^{\mathrm{ab}}$ & $3,55^{\mathrm{b}}$ \\
Proteína (\%) & $3,15^{\mathrm{a}}$ & $3,18^{\mathrm{b}}$ & $3,16^{\mathrm{a}}$ & $3,16^{\mathrm{a}}$ \\
NUL & $16,56^{\mathrm{a}}$ & $16,17^{\mathrm{a}}$ & $15,95^{\mathrm{a}}$ & $16,03^{\mathrm{a}}$ \\
(mmol/L) & & & & \\
IPPS (días) & $92,1^{\mathrm{a}}$ & $90,5^{\mathrm{a}}$ & $91,4^{\mathrm{a}}$ & $91,5^{\mathrm{a}}$ \\
IPP (días) & $137,0^{\mathrm{ab}}$ & $134,8^{\mathrm{a}}$ & $138,8^{\mathrm{b}}$ & $139,7^{\mathrm{b}}$ \\
$\begin{array}{l}\text { SC } \\
\text { (unidades) }\end{array}$ & $1,78^{\mathrm{a}}$ & $1,79^{\mathrm{ab}}$ & $1,82^{\mathrm{ab}}$ & $1,82^{\mathrm{b}}$ \\
\hline
\end{tabular}

a-b Referencias con letras diferentes dentro de las filas indican diferencias estadísticamente significativas $(\mathrm{P} \leq 0,05)$.

1 ME 305 MY = Producción de leche estandarizada a 305 días; LNRCS = logaritmo natural del recuento de células somáticas; NUL $=$ Nitrógeno ureico en leche; IPPS = intervalo parto primer servicio (días); IPP = intervalo parto preñez (días); $\mathrm{SC}=$ servicios por concepción.

valores menor y mayor de las LSM para LE LNRCS fueron en el verano de $2007(4,49)$ y en el verano de $1997(5,44)$, respectivamente.

\section{PORCENTAJE DE GRASA DE ESTANQUE}

El modelo final para porcentaje de grasa de la leche de estanque fue altamente significativo $(\mathrm{P} \leq 0,0001)$ y explicó el 31,6\% de la variación de este parámetro. Este modelo incluyó como variables independientes: número de vacas en ordeña, promedio de producción de leche del rebaño durante el día del muestreo, LNRCS, contenido de proteína de la muestra de estanque, promedio estandarizado de producción de leche (ME 305d), rebaño, estación y año de muestreo y su interacción (cuadro 4). La media para el \% de grasa (LE) \pm EE de todo el período fue 3,60 \pm 0,24\% Los valores menor y mayor de las LSM para LE grasa (\%) fueron en otoño de 1998 (3,43\%) y en verano de 2000 $(3,74 \%)$, respectivamente.

\section{PORCENTAJE DE PROTEÍNA DE LA LECHE DE ESTANQUE}

El modelo final para porcentaje de proteína (LE) fue altamente significativo $(\mathrm{P} \leq 0,0001)$ y explicó el $29,5 \%$ de la variación en el contenido de proteína. Incluyó como variables independientes: promedio de producción de leche del rebaño durante el día de muestreo, promedio estandarizado de producción de leche (ME 305d), LE LNRCS, grasa y contenido de NUL de la muestra (LE), rebaño, estación y año de muestreo y su interacción (cuadro 4). La media del porcentaje de proteína + EE de todo el período fue $3,17+0,12 \%$. El valor más bajo para las medias de los mínimos cuadrados fue en el verano de $2002(3,03 \%)$ y el valor más elevado fue durante el otoño de $1998(3,30 \%)$.

\section{NITRÓGENO UREICO EN LECHE}

El modelo final para LE NUL fue altamente significativo ( $\mathrm{P} \leq 0,0001)$ y explicó el 35,9\% de la variación del contenido de NUL (LE). Las variables independientes fueron: promedio de producción de leche del rebaño durante el día del muestreo, LE LNRCS y proteína, rebaño, estación y año de muestreo y su interacción (cuadro 4). La media del $\mathrm{NUL} \pm$ EE para todo el período fue 5,6 $\pm 1,8 \mathrm{mmol} / \mathrm{L}$. El valor más bajo para las medias de los mínimos cuadrados correspondió a la primavera de 2001 (4,1 mmol/L), con el mayor valor durante el verano de 2007 (8,1 mmol/L).

\section{PARÁMETROS DE LECHE DE ESTANQUE E ÍNDICES} REPRODUCTIVOS

El modelo final para IPPS fue altamente significativo (P $\leq$ 0,0001) y explicó el 64,7\% de la variación. Las variables explicativas fueron: número de vacas en ordeña, promedio de producción de leche del rebaño durante el día del muestreo, contenido de proteína y NUL de la muestra (LE), promedio estandarizado de producción de leche (ME 305d), rebaño y año.

El modelo final para IPP fue altamente significativo ( $\mathrm{P} \leq 0,0001)$ y explicó el $51,8 \%$ de la variación del IPP. Las variables explicativas fueron: número de vacas en ordeña, promedio de producción de leche del rebaño durante el día del muestreo, contenido de NUL de la muestra (LE), rebaño, estación y año (cuadro 4).

El modelo final para SC fue altamente significativo ( $\mathrm{P} \leq 0,0001)$ y explicó $41,7 \%$ de la variación. Las variables explicativas fueron: número de vacas en ordeña, promedio estandarizado de producción de leche (ME 305d) del rebaño, rebaño y año. Los índices reproductivos y los niveles de NUL a través de los años son presentados en la figura 2.

\section{DISCUSIÓN}

El recuento de células somáticas de la leche de estanque puede ser usado como un indicador del estado de salud mamaria de los planteles lecheros y es, a su vez, un reflejo de los RCS individuales dentro del rebaño (Lukas y col 2005). Durante el período examinado (11 años), los valores de LE LNRCS disminuyeron de 5,29 (489.000 células/ml) a 4,62 (309.000 células/ml), con un puntaje promedio de 4,77 (340.000 células/ml) (figura 1) y esta variación fue altamente significativa $(\mathrm{P} \leq 0,0001)$. Esta reducción podría explicarse por mejoras en las prácticas de manejo relacionadas con sanidad mamaria, implementadas 
Cuadro 4. Variables independientes y estimadores de los parámetros para el modelo de LE LNRCS $\left(\mathrm{r}^{2}=0,53, \mathrm{P} \leq 0,0001\right), \mathrm{LE} \%$ grasa $\left(r^{2}=0,32 ; P \leq 0,0001\right), L E \%$ proteína $\left(r^{2}=0,30, P \leq 0,0001\right)$, LE NUL $\left(r^{2}=0,36, P \leq 0,0001\right)$, CFS $\left(r^{2}=0,65, P \leq 0,0001\right)$, IPP $\left(\mathrm{r}^{2}=0,52, \mathrm{P} \leq 0,0001\right)$ y $\mathrm{SC}\left(\mathrm{r}^{2}=0,42, \mathrm{P} \leq 0,0001\right)$. Sólo los efectos significativos son presentados.

Explanatory variables and parameter estimates for LE LNRCS model $\left(\mathrm{r}^{2}=0.52, \mathrm{P} \leq 0.05\right), \mathrm{LE}$ fat $\%$ model $\left(\mathrm{r}^{2}=0.31 ; \mathrm{P} \leq 0.05\right), \mathrm{LE}$ protein \% model $\left(\mathrm{r}^{2}=0.30, \mathrm{P} \leq 0.05\right)$, LE NUL model $\left(\mathrm{r}^{2}=0.36, \mathrm{P} \leq 0.05\right)$, CFS $\left(r^{2}=0.65, P \leq 0.0001\right)$, IPP model $\left(r^{2}=0.52, P \leq 0.05\right)$, and $S C\left(r^{2}=0.42\right.$, $\mathrm{P} \leq 0.0001)$ Only significant effects are presented.

\begin{tabular}{|c|c|c|c|}
\hline Variables independientes & Estimador & $\mathrm{EEM}^{2}$ & $\mathrm{P}$ \\
\hline \multicolumn{4}{|l|}{ LE LNRCS } \\
\hline \# de vacas en ordeña (cada 10 vacas) & 0,01 & 0,003 & $<0,0001$ \\
\hline \# de vacas primíparas (cada 10 vacas) & $-0,05$ & 0,005 & $<0,0001$ \\
\hline Producción de leche promedio del rebaño ${ }^{1}$ & $-0,027$ & 0,002 & $<0,0001$ \\
\hline LE grasa $\%$ (cada $0,1 \%$ ) & 0,023 & 0,022 & $<0,0001$ \\
\hline LE proteína\% (cada 0,1\%) & 0,02 & 0,004 & $<0,0001$ \\
\hline LE NUL (cada 1 mmol/L) & 0,03 & 0,001 & 0,0015 \\
\hline ME $305 \mathrm{MY}^{2}($ cada $1.000 \mathrm{~kg})$ & 0,026 & 1,0 & 0,0085 \\
\hline \multicolumn{4}{|l|}{ LE\% grasa } \\
\hline \# de vacas en ordeña (cada10 vacas) & $-0,0029$ & 0,0013 & 0,029 \\
\hline Producción de leche promedio del rebaño & $-0,025$ & 0,0012 & $<0,0001$ \\
\hline LE LNRCS (cada 1 unidad) & 0,048 & 0,0046 & $<0,0001$ \\
\hline LE proteína\% (cada 0,1\%) & 0,029 & 0,0018 & $<0,0001$ \\
\hline ME 305 MY (cada $1.000 \mathrm{~kg}$ ) & 0,04 & 0,0046 & $<0,0001$ \\
\hline \multicolumn{4}{|l|}{ LE\% proteína } \\
\hline Producción de leche promedio del rebaño & 0,0027 & 0,0006 & $<0,0001$ \\
\hline LE LNRCS & 0,012 & 0,0024 & $<0,0001$ \\
\hline LE grasa $\%$ (cada $0,1 \%$ ) & 0,084 & 0,005 & $<0,0001$ \\
\hline LE NUL (cada 1 mmol/L) & $-0,0006$ & 0,0002 & 0,02 \\
\hline ME 305d MY (cada 1.000 kg) & 0,0082 & 0,0024 & 0,0008 \\
\hline \multicolumn{4}{|l|}{ LE NUL } \\
\hline Producción de leche promedio del rebaño & 0,224 & 0,025 & $<0,0001$ \\
\hline LE LNRCS (cada 1 unidad) & 0,311 & 0,098 & 0,0015 \\
\hline LE proteína\% (cada $0,1 \%$ ) & $-0,094$ & 0,040 & 0,02 \\
\hline \multicolumn{4}{|l|}{ IPPS } \\
\hline \# de vacas en ordeña (cada10 vacas) & $-0,3$ & 0,0004 & $<0,0001$ \\
\hline Producción de leche promedio del rebaño & $-0,66$ & 0,05 & $<0,0001$ \\
\hline LE proteína $\%$ (cada $0,1 \%$ ) & 0,25 & 0,08 & 0,03 \\
\hline LE NUL (cada 1 mmol/L) & 0,04 & 0,022 & 0,04 \\
\hline ME 305d MY (cada 1.000 kg) & $-0,1$ & 0,03 & $<0,0001$ \\
\hline IPP & & & \\
\hline \# de vacas en ordeña (cada10 vacas) & $-0,1$ & 0,0008 & 0,04 \\
\hline Producción de leche promedio del rebaño & $-0,37$ & 0,1 & 0,0006 \\
\hline LE NUL (cada $1 \mathrm{mmol} / \mathrm{L}$ ) & 0,09 & 0,04 & 0,03 \\
\hline $\mathrm{SC}$ & & & \\
\hline \# de vacas en ordeña (cada10 vacas) & 0,005 & 0,0001 & $<0,0001$ \\
\hline ME 305d MY (cada 1.000 kg) & 0,031 & 0,0006 & $<0,0001$ \\
\hline
\end{tabular}

en parte por el impacto que los RCS han tenido en el precio de leche recibido por los productores. En Chile, el procedimiento para establecer el precio de leche pagado por las plantas procesadoras incluye un esquema de pago que considera bonos y castigos de acuerdo a parámetros como recuento bacteriano, porcentaje de grasa y proteína y RCS de estanque. Estas exigencias han sido incorporadas gradualmente en el tiempo, dependiendo de cada planta procesadora y el inicio del período en análisis coincide con la incorporación de RCS y proteína en las pautas de pago en el área en estudio. Algunas prácticas asociadas con menores LNRCS $(<3)$ en lecherías chilenas han sido reportadas previamente (Tadich y col 2003). Ellas incluyen el despunte preordeña, el lavado de pezones con agua mezclada con desinfectante, el chequeo de ubre y pezones previo a la ordeña y el registro de RCS individuales. La disponibilidad de RCS individuales como parte del control lechero oficial es común a las lecherías incluidas en este estudio y el uso de esta información es una práctica frecuente.

Uno de los resultados de este estudio fue una asociación negativa entre LE LNRCS y el promedio de producción de leche del rebaño el día del muestreo. Este hallazgo podría asociarse principalmente con dos factores. Primero, altos niveles de producción se relacionarían con progreso genético y mejores prácticas de manejo que podrían tener un efecto en el nivel de salud mamaria (Wilson y col 1997, Barkema y col 1998). Un segundo factor podría ser el efecto de dilución que ha sido reportado previamente. Emanuelson y Funke (1991) encontraron una asociación negativa entre producción de leche promedio y RCS de estanque, indicando que la disminución en RCS durante los años recientes en rebaños lecheros en Suecia sería en parte un enmascaramiento debido a un incremento simultáneo en los niveles de producción de leche. Este efecto de dilución ha sido también reportado en un estudio que encontró que rebaños de mayor tamaño estaban asociados con menores RCS de estanque (Van Schaik y col 2002).

Una tendencia hacia mayores niveles de producción de leche ha sido reportada previamente en lecherías en la misma área en estudio (Meléndez y Pinedo 2007). La producción de leche estandarizada a 305 días se incrementó en más de $1.500 \mathrm{~kg}(\mathrm{P}<0,05)$ entre 1990 y 2003; por lo tanto, podría esperarse un efecto de dilución, explicando en parte la reducción en LE LNRCS en la población en estudio.

Nuestro análisis estimó una asociación negativa entre LE LNRCS y el número de vacas en primera lactancia que concuerda con lo reportado por Berry y col (2007) y podría relacionarse con un menor tiempo de exposición a patógenos y a una mejor conformación de la ubre en vacas primíparas.

Desde mediados de los 70, los productores de leche chilenos han utilizado semen congelado importado desde Norteamérica con el propósito de incrementar la producción de leche y sólidos incorporando la genética Holstein en 
Figura 1. Medias de los mínimos cuadrados \pm EEM para LE LNRCS, grasa $(\%)$ y proteína (\%) durante el período 1997 2007.

Least squares means \pm SEM for bulk tank LNRCS, fat $(\%)$ and protein (\%) during the period 1997-2007.

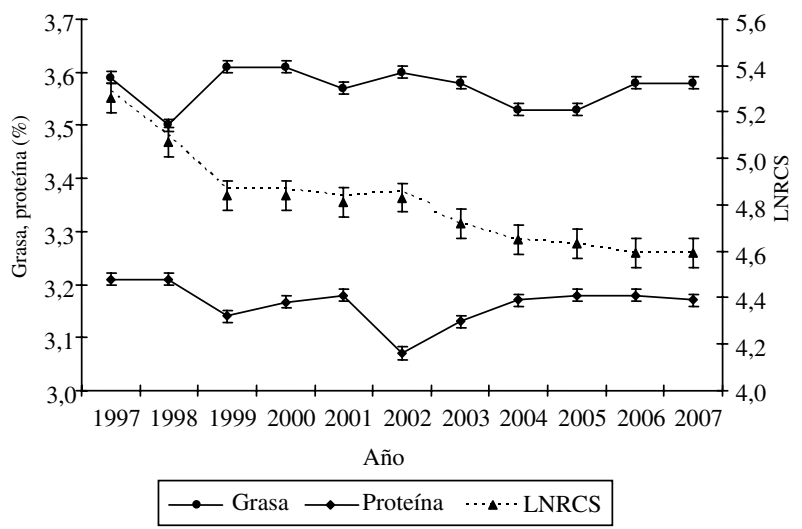

Figura 2. (a) Índices reproductivos (LSM) para el ganado lechero de la zona centro-sur de Chile entre los años 1997 y 2007. IPP = intervalo parto preñez (días); $\mathrm{SC}=$ servicios por concepción; IPPS = intervalo parto primer servicio (días). (b) Medias de los mínimos cuadrados \pm EEM para LE NUL ( $\mathrm{mmol} / \mathrm{L}$ ) durante el período 1997-2007.

(a) Reproductive indexes (LSM) in central-southern Chilean Holstein cattle between 1997 and 2007. IPP = days from calving to conception; $\mathrm{SC}=$ services per conception; IPPS $=$ days from calving to first service interval. (b) Least squares means \pm SEM for bulk tank NUL (mmol/L) during the period 1997-2007.

(a)

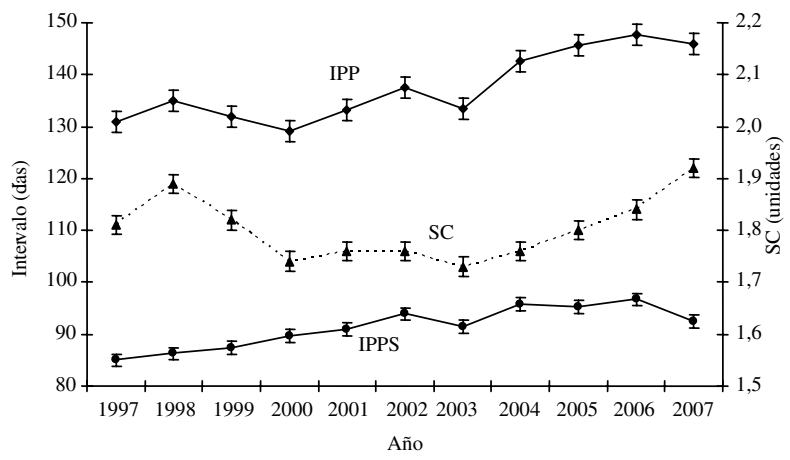

(b)

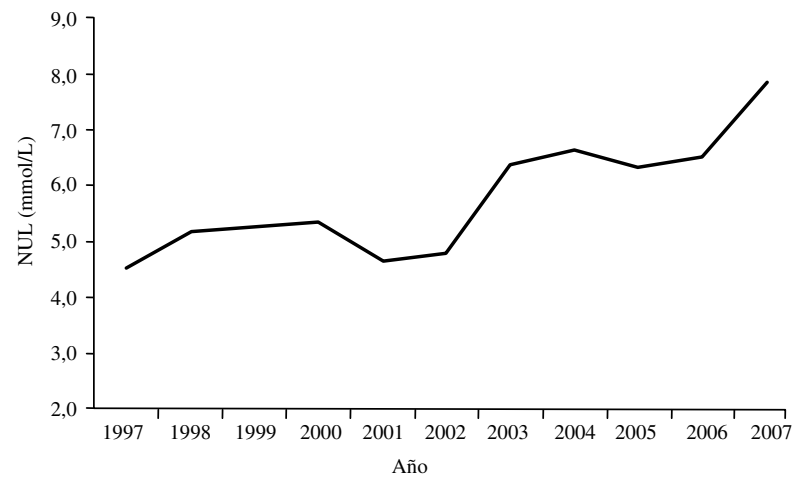

la raza doble propósito local (Frisón Europeo). Una tendencia genética positiva para producción de leche, grasa y proteína estandarizada a ME 305d se ha reportado previamente en rebaños lecheros chilenos (Elzo y col 2004). Jara y col (2004) estimaron una respuesta a la selección correlacionada para toros Holstein de EE.UU. en la misma área de estudio. Los valores estimados para la respuesta a la selección fueron menores que las respuestas reportadas en rebaños de EE.UU., representando el $34 \%$ y el $26 \%$ de la respuesta a selección observada para producción de leche y grasa en ese país, respectivamente. En concordancia con esta información, el porcentaje de grasa y proteína de estanque en nuestro estudio no evidenció una tendencia clara a través del tiempo. El porcentaje promedio de grasa para el período completo fue $3,60 \%$ y el valor más reciente fue similar $(3,58 \%)$. Igualmente, el promedio para proteína fue $3,17 \%$ con este mismo valor para el 2007.

El nitrógeno ureico en leche es considerado un componente nitrogenado no proteico normal de la leche y ha sido usado para monitorear el estatus nutricional de las vacas lecheras durante su lactancia (Jonker y col 1999, Mitchell y col 2005). Cuando la dieta de rumiantes contiene un nivel adecuado de energía, los niveles de NUL han sido reconocidos como un indicador preciso del nivel nutricional de proteína. Se ha sugerido también que las variaciones en NUL están relacionadas con el balance entre proteína y energía de la dieta consumida (Jonker y col 1999), con valores entre 10 y $16 \mathrm{mg} / \mathrm{dL}$ (3,6 y 5,7 mmol/L) para una lactancia típica. En nuestro estudio los valores para NUL de estanque se mantuvieron dentro de los rangos normalmente recomendados $(<5,4 \mathrm{mmol} / \mathrm{L})$ durante 1997-2002. Sin embargo, estos niveles se incrementaron significativamente el año $2003(6,4 \mathrm{mmol} / \mathrm{L})$ con un valor aún más extremo para el 2007 (7,8 mmol/L). Esto podría indicar un desbalance en el aporte de proteína y energía de la dieta y en el metabolismo del nitrógeno en esta población durante los últimos 5 años en estudio. Dado el incremento sostenido en producción de leche en este periodo, los altos niveles de NUL pudieran estar relacionados con excesos en el contenido de proteína cruda más que con bajos niveles de energía de las dietas utilizadas en esos rebaños. Broderick y col (1997) analizaron el efecto de los factores dietarios y animales en la relación entre NUL y la evaluación del estado proteico, indicando regresiones significativas sobre los niveles de NUL para proteína cruda en la dieta (PC), PC por megacaloría de energía neta de lactancia en la dieta $\mathrm{y}$ exceso en la ingesta de $\mathrm{N}$.

Nuestros resultados están en parcial acuerdo con aquellos reportados por Hojman y col (2004). En ese estudio se encontraron relaciones positivas entre la concentración de NUL y producción de grasa (\%) en leche. Contrariamente, las asociaciones entre NUL y proteína (\%) y RCS fueron negativas. En nuestro estudio no se encontró una asociación entre NUL y grasa y hubo una asociación positiva con LNRCS. Además, los mismos autores reportaron un efecto de estación en NUL con los más altos niveles durante los 
meses de verano (Hojman y col 2004); por el contrario, el efecto estación no estuvo asociado con los niveles de NUL en nuestro estudio.

Los valores de NUL de leche de estanque están asociados con los niveles individuales de las vacas (Arunvipas y col 2004). Nuestro estudio arrojó valores de NUL para el período 1998-2001 de entre 4,6 y 5,4 mmol/L, que son similares a valores individuales de NUL reportados por un trabajo previo conducido en la misma área (Pedraza y col 2006). Ese estudio reportó valores de NUL para vacas en primera y segunda o más lactancias de 13,5 y $15,5 \mathrm{mg} / \mathrm{dL}$ (4,8 y $5,5 \mathrm{mmol} / \mathrm{dL})$, respectivamente. Además, en concordancia con nuestros resultados, hubo una asociación negativa entre proteína en leche (\%) y NUL tanto como una asociación positiva entre RCS y NUL a nivel de vacas individuales.

Nuestros resultados indicaron un incremento sostenido del IPPS en el tiempo $(\mathrm{P} \leq 0,05)$ y una asociación significativa entre IPPS y las variables LE proteína \% y LE NUL. Aumentos en estas dos variables se asociaron a un mayor número de días al primer servicio postparto. En estudios previos no existe una clara mención sobre esta asociación dado que la mayoría de los estudios se centran en los días entre el parto y la concepción (IPP) o en la tasa de concepción al primer servicio (Meléndez y col 2000, Guo y col 2004).

El intervalo parto preñez (IPP) está afectado por el período de espera voluntario, la tasa de detección de calores, las fallas en el retorno a la ciclicidad, la tasa de concepción y la tasa de abortos del rebaño (Lucy 2001). En nuestro estudio, el IPP se incrementó de 130,8 a 145,9 entre los años 1997 y 2007. En un estudio reciente, Hare y col (2006) usando sobre un millón de lactancias de animales Holstein presentaron valores de IPP similares y consistentes con los valores para la población chilena reportada en nuestro trabajo. Nuestros resultados indican que los índices reproductivos del ganado lechero de la zona centro-sur de Chile se han deteriorado entre 1997 y 2007, lo que es consistente con observaciones en otros países (Lucy 2001).

Entre los componentes de la leche de estanque sólo NUL evidenció una asociación con el IPP y ésta fue altamente significativa y negativa. Sin embargo, esta relación no es estrictamente de causalidad, dado que estas dos variables pueden estar relacionadas con factores en común, tales como una elevada producción de leche y nivel genético del rebaño y pueden, por lo tanto, ser una potencial fuente de sesgo por una asociación sólo aparente. Como ejemplo, el incremento del nivel genético ha determinado una mayor producción de leche que puede a su vez estar asociada con un mejor manejo nutricional (altos niveles de proteína en la dieta; consecuentemente NUL). Además, una alta producción de leche se relaciona a un más pronunciado desbalance energético que, a su vez, se asocia a una fertilidad más pobre (Butler y Smith 1989). Por otro lado, existen numerosos estudios reportando un impacto negativo de excesos de nitrógeno ureico en la reproducción del ganado lechero (Canfield y col 1990, Meléndez y col 2000, Hojman y col 2004). En otro estudio realizado en Chile, Wittwer y col (1999) evaluaron la variación estacional de los niveles de NUL a nivel de individuos y examinaron su relación potencial con los niveles de fertilidad de diferentes rebaños bajo condiciones de pastoreo. En concordancia con nuestros resultados, diferentes niveles de urea se asociaron con variadas eficiencias reproductivas. El riesgo de concepción al primer servicio fue menor en rebaños con NUL de estanque $>20,4 \mathrm{mg} / \mathrm{dL}(7,3 \mathrm{mmol} / \mathrm{L})$ comparado con rebaños con concentraciones de NUL $<14 \mathrm{mg} / \mathrm{dL}$ (5,0 mmol/L) al momento de la inseminación (50,7\% y 73,8\%, respectivamente). El estudio concluyó que elevadas concentraciones de urea de estanque estaban asociadas con un menor riesgo de concepción al primer servicio en sistemas pastoriles. Debido a que el IPP depende del riesgo de concepción, puede asumirse que la asociación entre NUL de estanque y IPP en el presente estudio tiene un potencial sentido biológico. El parámetro número de servicios por concepción sólo resultó asociado al número de vacas en ordeña y a los niveles promedio de leche estandarizada (ME 305 d) y, a diferencia del IPP, no se encontró un efecto significativo para los niveles de NUL. Este resultado coincide con lo presentado por Carroll y col (1988), donde vacas alimentadas con niveles altos y bajos de proteína cruda (resultantes en niveles correspondientes de urea plasmática) no evidenciaron diferencias en el número de servicios a la preñez.

Contrario a reportes previos, altos RCS no se vieron asociados a niveles deteriorados de fertilidad. Schrick y col (2001) describieron para la mastitis subclínica un efecto en fertilidad similar al producido por la mastitis clínica y RCS elevados se asociaron a un aumento en los días al primer servicio y en el intervalo parto preñez (Pinedo y col 2009). Sin embargo, en ambos casos, el estudio se basó en RCS y parámetros reproductivos individuales que pueden ser más sensibles que los datos prediales analizados en este estudio.

Una limitación del presente estudio es que los índices reproductivos utilizados en el análisis de la potencial asociación entre fertilidad y composición de la leche de estanque incluyeron todas las vacas afectadas (con un primer servicio o preñadas) al momento del muestreo. Esto hace que estos índices sean menos sensibles y evidencien el efecto de otras variables con alguna demora. Sin embargo, dada la magnitud del periodo en análisis el efecto de esa limitación es reducido.

En nuestro estudio se concluye que los cambios más significativos en la composición de la leche de estanque en rebaños lecheros en la zona centro-sur de Chile, durante los últimos 10 años, correspondieron a una disminución en RCS y a un incremento en NUL. Esos cambios reflejan una mejora en el nivel de sanidad mamaria, calidad de leche y niveles de producción. Las concentraciones de NUL en leche de estanque fueron altas durante los últimos 5 años en análisis y dependieron de factores tales como nivel de producción de leche, porcentaje de proteína, mes y año. NUL fue el componente con la más notoria asociación con los parámetros reproductivos. Más antecedentes sobre los niveles de incorporación de proteína en la dieta de esta población debieran ser evaluados en detalle. 


\section{RESUMEN}

El objetivo de este estudio fue describir y evaluar la dinámica de los recuentos de células somáticas (RCS), el nitrógeno ureico (NUL), el porcentaje de grasa y el porcentaje de proteína de la leche de estanque (LE) y analizar su asociación con índices reproductivos, considerando muestras mensuales de leche de estanque de 187 rebaños lecheros ( 12.000 vacas lecheras) en la zona centro-sur de Chile entre 1997 y 2007. Los índices reproductivos incluidos en el estudio fueron intervalo parto primer servicio (IPPS, d), intervalo parto preñez (IPP, d) y servicios por concepción (SC). Los RCS de estanque resultaron positivamente asociados con tamaño de rebaño, producción de leche (ME 305d), sólidos en leche y NUL. E nitrógeno ureico de la leche de estanque resultó positivamente asociado con producción de leche y LE RCS. El promedio del intervalo parto primer servicio fue de 92,5 d y mostró una asociación positiva con los niveles de proteína de estanque y NUL. El promedio del intervalo parto preñez fue 138,9 d y evidenció una asociación positiva con LE NUL. Se concluye que los cambios más significativos en los componentes la leche de estanque durante los últimos 10 años en planteles lecheros de la zona centro sur de Chile correspondieron a una disminución en RCS $y$ a un incremento en NUL. Los cambios en RCS reflejan una mejora en sanidad mamaria, calidad y niveles de producción de leche. Las concentraciones de NUL en leche de estanque fueron elevadas durante los últimos 5 años del periodo en estudio y dependieron de factores tales como producción de leche, porcentaje de proteína, mes y año de muestreo. NUL resultó el componente con la asociación más notoria con los parámetros reproductivos en análisis.

\section{AGRADECIMIENTOS}

Los autores agradecen a INSECABIO Ltda. (Chile) por su apoyo en el financiamiento de este estudio y por autorizar el análisis de la base de datos del control lechero oficial.

\section{REFERENCIAS}

Ali AKA, GE Shook. 1980. An optimum transformation for somatic cell concentration in milk. J Dairy Sci 63, 487-490.

Arunvipas P, JA Van Leeuwen, IR Dohoo, GP Keefe. 2004. Bulk tank milk urea nitrogen: Seasonal patterns and relationship to individual cow milk urea nitrogen values. Can J Vet Res 68, 169-174.

Barkema HW, YH Schukken, TJGM Lam, ML Beiboer, G Benedictus, A Brand. 1998. Management practices associated with low, medium, and high somatic cell counts in bulk milk. J Dairy Sci 81, 1917-1927.

Berry DP, JM Lee, KA Macdonald, K Stafford, L Matthews, JR Roche. 2007. Associations among body condition score, body weight, somatic cell count, and clinical mastitis in seasonally calving dairy cattle. J Dairy Sci 90, 637-648.

Broderick GA, MK Clayton. 1997. A statistical evaluation of animal and nutritional factors influencing concentrations of milk urea nitrogen. J Dairy Sci 80, 2964-2971.

Buckley F, K O’Sullivan, JF Mee, RD Evans, P Dillon. 2003. Relationships among milk yield, body condition, cow weight, and reproduction in spring-calved Holstein-Friesians. J Dairy Sci 86, 2308-2319.

Butler WR, RD Smith. 1989. Interrelationships between energy balance and postpartum reproductive function in dairy cattle. J Dairy Sci 72, 767-783.

Canfield RW, CJ Sniffen, WR Butler. 1990. Effects of excess degradable protein on postpartum reproduction and energy balance in dairy cattle. J Dairy Sci 73, 2342-2349.

Carroll DJ, BA Barton, GW Anderson, RD Smith. 1988. Influence of protein intake and feeding strategy on reproductive performance of dairy cows. J Dairy Sci 71, 3470-3481.

Elzo MA, A Jara, N Barria. 2004. Genetic parameters and trends in the Chilean multibreed dairy cattle population. J Dairy Sci 87, 1506-1518.

Emanuelson U, H Funke. 1991. Effect of milk yield on relationship between bulk milk somatic cell count and prevalence of mastitis. J Dairy Sci 74, 2479-2483.
Godden SM, DF Kelton, KD Lissemore, JS Walton, KE Leslie, JH Lumsden. 2001. Milk urea testing as a tool to monitor reproductive performance in Ontario dairy herds. J Dairy Sci 84, 1397-1406.

Guo K, E Russek-Cohen, MA Varner, RA Kohn. 2004. Effects of Milk Urea Nitrogen and Other Factors on Probability of Conception of Dairy Cows. J Dairy Sci 87, 1878-1885.

Hare E, HD Norman, JR Wright. 2006. Trends in calving ages and calving intervals for dairy cattle breeds in the United States. J Dairy Sci 89, 365-370.

Hojman D, O Kroll, G Adin, M Gips, B Hanochi, E Ezra. 2004. Relationships between milk urea and production, nutrition, and fertility traits in Israeli dairy herds. J Dairy Sci 87, 1001-1011.

Jara A, A Guzmán, M Peña, MJ García, N Barría. 2004. Selection response for milk production of United States Holstein bulls in the provinces of Bío-Bío and Malleco, Chile. Arch Med Vet 37, 15-22.

Jayarao BM, SR Pillai, AA Sawant, DR Wolfgang, NV Hegde. 2004. Guidelines for monitoring bulk tank milk somatic cell and bacterial counts. J Dairy Sci 87, 3561-3573.

Jonker JS, RA Kohn, RA Erdman. 1999. Milk urea nitrogen target concentrations for lactating dairy cows fed according to National Research Council recommendations. J Dairy Sci 82, 1261-1273.

Losinger WC. 2005. Economic impacts of reduced milk production associated with an increase in bulk-tank somatic cell count on US dairies. J Am Vet Med Assoc 226, 1652-1658.

Lucy MC 2001. Reproductive loss in high-producing dairy cattle: Where will it end? J Dairy Sci 84, 1277-1293.

Lukas JM, DM Hawkins, ML Kinsel, JK Reneau. 2005. Bulk tank somatic cell counts analyzed by statistical process control tools to identify and monitor subclinical mastitis incidence. J Dairy Sci 88, 3944-3952.

Meléndez P, A Donovan, J Hernández. 2000. Milk urea nitrogen and infertility in Florida Holstein cows. J Dairy Sci 83, 459-463.

Meléndez P, P Pinedo. 2007. The association between reproductive performance and milk yield in Chilean Holstein cattle. J Dairy Sci 90, 184-192.

Mitchell RG, GW Rogers, CD Dechow, JE Vallimont, JB Cooper, U Sander-Nielsen, JS Clay. 2005. Milk urea nitrogen concentration: heritability and genetic correlations with reproductive performance and disease. J Dairy Sci 88, 4434-4440.

Patton J, DA Kenny, S McNamara, JF Mee, FP O'Mara, MG Diskin, JJ Murphy. 2007. Relationships among milk production, energy balance, plasma analytes, and reproduction in Holstein-Friesian cows. J Dairy Sci 90, 649-658.

Pedraza C, A Mansilla, F Merucci, P Pinedo. H Contreras. 2006. Urea milk contents in dairy cows of Bio-Bio region. Agricultura Técnica (Chile) 66, 264-270.

Pinedo, P, P Meléndez, JA Villagómez-Cortés, C Risco. 2009. Effect of High Somatic Cell Counts on Reproductive Performance of Chilean Dairy Cattle. J Dairy Sci 92, 1575-1580.

SAS. 2003. SAS/STAT Software Change and enhancements through release 9.1 for Windows. SAS Inst Inc, Cary, NC, USA.

Schrick FN, ME Hockett, AM Saxton, MJ Lewis, HH Dowlen, SP Oliver. 2001. Influence of subclinical mastitis during early lactation on reproductive parameters. J Dairy Sci 84, 1407-1412.

Schukken YH, J Buurman, A Brand, D Van der Geer, FJ Grommers. 1990. Population dynamics of bulk milk somatic cell counts. J Dairy Sci 73, 1343-1350.

Tadich N, J Kruze, G Locher, LE Green. 2003. Risk factors associated with BMSCC greater than 200,000 cells $/ \mathrm{ml}$ in dairy herds in southern Chile. Prev Vet Med 58, 15-24.

Van Schaik G, M Lotem, YH Schukken. 2002. Trends in somatic cell counts, bacterial counts, and antibiotic residue violations in New York State during 1999-2000. J Dairy Sci 85, 782-789.

Wenz JR, SM Jensen, JE Lombard, BA Wagner, RP Dinsmore. 2007. Herd management practices and their association with bulk tank somatic cell count on United States dairy operations. J Dairy Sci 90, 3652-3659.

Wilson DJ, HH Das, RN González, PM Sears. 1997. Association between management practices, dairy herd characteristics, and somatic cell count of bulk tank milk. J Am Vet Med Assoc 210, 1499-1502.

Wittwer FG, P Gallardo, J Reyes, H Optiz. 1999. Bulk milk urea concentrations and their relationship with cow fertility in grazing dairy herds in southern Chile. Prev Vet Med 38, 159-166. 